Anal. Chem. 87 (2015) 12151-12160 Doi: 10.1021/acs.analchem.5b02994

\title{
Selected ion flow-drift tube mass spectrometry, SIFDT-MS: quantification of volatile compounds in air and breath.
}

\author{
Anatolii Spesyvyi ${ }^{1,2}$, David Smith ${ }^{3}$ and Patrik Španěl ${ }^{1 *}$ \\ ${ }^{1}$ J. Heyrovsky Institute of Physical Chemistry of Science, Academy of Science of the Czech Republic, \\ Dolejškova 3, 18223 Prague 8, Czech Republic \\ ${ }^{2}$ Department of Surface and Plasma Science, Faculty of Mathematics and Physics, Charles University in \\ Prague, V Holešovičkách 2, 18000 Prague, Czech Republic \\ ${ }^{3}$ Institute for Science and Technology in Medicine, School of Medicine, Keele University, Thornburrow \\ Drive, Hartshill, Stoke-on-Trent ST4 7QB, UK
}

\begin{abstract}
A selected ion flow drift tube mass spectrometric analytical technique, SIFDT-MS, is described that extends the established selected ion flow tube mass spectrometry, SIFT-MS, by the inclusion of a static but variable $E$-field along the axis of the flow tube reactor in which the analytical ion-molecule chemistry occurs. The ion axial speed is increased in proportion to the reduced field strength $E / N$ ( $N$ is the carrier gas number density) and the residence/reaction time, $t$, which is measured by Hadamard transform multiplexing, is correspondingly reduced. To ensure a proper understanding of the physics and ion chemistry underlying SIFDT-MS, ion diffusive loss to the walls of the flow-drift tube and the mobility of injected $\mathrm{H}_{3} \mathrm{O}^{+}$ions have been studied as a function of $E / N$. It is seen that the derived diffusion coefficient and mobility of $\mathrm{H}_{3} \mathrm{O}^{+}$ions are consistent with those previously reported. The rate coefficient has been determined at elevated $\mathrm{E} / \mathrm{N}$ for the association reaction of the $\mathrm{H}_{3} \mathrm{O}^{+}$reagent ions with $\mathrm{H}_{2} \mathrm{O}$ molecules, which is the first step in the production of $\mathrm{H}_{3} \mathrm{O}^{+}\left(\mathrm{H}_{2} \mathrm{O}\right)_{1,2,3}$ reagent hydrate ions. The production of hydrated analyte ion was also experimentally investigated. The analytical performance of SIFDT-MS is demonstrated by the quantification of acetone and isoprene in exhaled breath. Finally, the essential features of SIFDT-MS and SIFT-MS are compared, notably pointing out that a much lower speed of the flow-drive pump is required for SIFDT-MS, which facilitates development of smaller cost-effective analytical instruments for real time breath and fluid headspace analyses.
\end{abstract}

Key words: SIFT-MS, selected ion flow-drift tube mass spectrometry, SIFDT-MS, ion molecule reactions, diffusion, mobility, drift time, reduced field $E / N$

Corresponding Author: *P. Španěl. E-mail: spanel@jh-inst.cas.cz 
There is a growing and constant demand for analytical techniques that can accurately quantify in real time the trace gases in ambient air, exhaled breath and the headspace of liquids, especially volatile organic compounds, VOCs. Some areas in which such analyses are important have been reviewed recently., These gaseous media are usually humid, especially so in the case of exhaled breath, and so ideally the analytical method must allow quantification of the VOCs without de-humidification that can compromise the sample. Furthermore, size, weight and cost of instrumentation are important issues and versatility is very desirable for research applications when a great variety of VOCs need to be detected and analysed..$^{3-5}$ In this regard, gas chromatography with mass spectrometry, GC-MS, has made a major contribution to gas analysis, but it is not a real time technique. Whilst nanomaterial-based sensors, $\underline{6}$ laser spectroscopic

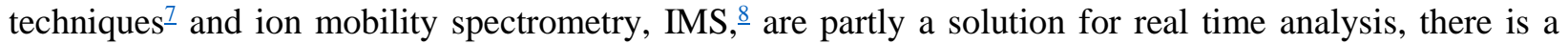
need for further development of techniques based on chemical ionization during defined reaction times, exemplified by selected ion flow tube mass spectrometry, SIFT-MS, $\stackrel{1}{-}$ and proton transfer reaction mass spectrometry, PTR-MS. $, 9, \underline{10}$ Both of these techniques are widely used for real time trace gas analysis in various areas and are able to accurately quantify trace compounds and biomarkers in air and exhaled breath. Yet there are clear intrinsic differences between these techniques which reflect their relative strengths and weaknesses as analytical tools that need to be appreciated in further development of analytical methods based on gas phase ion molecule reactions.

PTR-MS is a flow-drift tube system in which a relatively high electric field exists along the axis of the flow-drift tube, expressed as the reduced field strength $E / N$, where $E$ is the axial electric field strength and $N$ is the number density of the buffer gas molecules. The ion-molecule reaction time is determined by $E / N$ and is reduced below that appropriate to a field-free flow tube of the same length. The associated increase in kinetic energy of the analyte ions and their collisions with the buffer gas air molecules can promote collisional dissociation but at the same time inhibit ion hydration. The reagent ions, most commonly $\mathrm{H}_{3} \mathrm{O}^{+}$, are injected directly from a discharge ion source without $m / z$ (mass-to-charge ratio) selection and so the ion beam from the source can be partially contaminated with "impurity" ions, especially $\mathrm{NO}^{+}$and $\mathrm{O}_{2}{ }^{+}$. However, this allows relatively large ion currents to be injected into the flow-drift tube and hence provides high analytical sensitivity. The buffer gas is the sample gas to be analysed; whilst this also increases the analytical sensitivity, the complexity and humidity of such multi-component medium, especially exhaled breath $\left(\mathrm{N}_{2}, \mathrm{O}_{2}, \mathrm{CO}_{2}, \mathrm{H}_{2} \mathrm{O}\right.$, Ar), can complicate the analytical ion chemistry even though the majority buffer gas molecules are relatively inert. $\frac{11}{}$ Thus, interpretation of the mass spectra of the reagent and analyte ions can be very complicated, which can compromise the trace gas quantification unless calibration procedures are carried out. $\frac{12, \underline{13}}{2}$

SIFT-MS is a flow tube system in which reagent ions are formed in a microwave discharge and selected according to their mass-to-charge ratio, $\mathrm{m} / \mathrm{z}$, by a quadrupole mass filter and injected into the flow tube. Thus, rapid switching between reagent ions $\mathrm{H}_{3} \mathrm{O}^{+}, \mathrm{NO}^{+}$and $\mathrm{O}_{2}{ }^{+}$can be achieved which realises cleaner ion chemistry and enhances analytical power. The price paid for this is a lower ion injection current and hence reduced analytical sensitivity. The ion reaction time is longer than it is when an electric field is present, which is equates to higher analytical sensitivity; it is calculated from the pumping speed of the carrier gas and cannot be readily varied for a given instrument. The carrier gas is usually inert helium with only a small admixture of the sample gas to be analysed which introduces a smaller fraction of interfering molecules, notably water molecules, into the thermal energy reactor. Thus, the analysis relies on truly thermal ion chemistry that is well understood following investigations of numerous ion-molecule reactions. ${ }^{14}$ However, even at low water molecule number densities a complicating issue is the efficient hydration of the reagent and analyte ions that occurs under thermal (low) interaction energies and this phenomenon must be accounted for to achieve accurate analyses. A further constraint of SIFT-MS is the need for heavy carrier gas drive pumps to establish the rapid carrier gas flow speed required to reduce 
diffusion losses of reagent and analyte ions to the flow tube walls. In the Profile 3 (Instrument Science, Crewe, UK) SIFT-MS instrument $\frac{15}{15}$ the drive pump thus represents almost half of the weight of the instrument and in Voice 200 (Syft Technologies Ltd. Christchurch, New Zealand) an even larger drive pump is used. In PTR-MS, smaller drive pumps are required ${ }^{3}$. Nevertheless, disadvantages of both PTRMS and SIFT-MS instruments, as currently available, are their size, weight and cost, which inhibit wider application. $\underline{4}$

In order to further improve the current SIFT-MS technique and to respond to recognised analytical needs, as précised above, we have constructed a new instrument using a reactor flow-drift tube instead of a flow tube. The construction of this selected ion flow-drift tube, SIFDT, instrument is described in the Experimental Section. The concept is to exploit a low strength embedded $E$-field to increase the transport speed of the reagent ions (i.e. $\mathrm{H}_{3} \mathrm{O}^{+}, \mathrm{NO}^{+}$and $\mathrm{O}_{2}{ }^{+\bullet}$ as established in SIFT-MS) along the flow-drift tube in order to suppress ion diffusive loss thus increasing analytical sensitivity, and to allow a smaller, lower speed carrier gas drive pump to be used. As is shown later, $E / N$ values can be used that are much lower than those adopted in PTR-MS, which minimizes analyte ion collisional dissociation yet reduces the hydration of reagent and analyte ions. The latter feature can be exploited to distinguish between bare primary analyte ions and hydrated analyte ions, which is sometimes difficult in SIFT-MS. $\frac{16,17}{17}$ The reaction time for the analytical ion-molecule reactions can be rapidly changed by varying $E / N$ and quickly determined by adopting the Hadamard transform multiplexing as reported in detail in a recent publication. ${ }^{18}$ The SIFDT-MS analytical technique is thus a logical development of SIFT-MS that retains all the desirable features and advantages of SIFT-MS whilst removing the need for a large drive pump and adding a new facility to change the conditions under which the analytical ion-molecule reactions occur.

The first objective of the research work reported here was to assess the basic operation of SIFDT through the measurement of those physical transport parameters traditionally considered in drift tube physics, viz. gaseous ion diffusion, drift velocity and mobility, and how they depend on the nature, flow rates and pressures of the sample gas and carrier/buffer gas, and the reduced field strength, $E / N$. The second objective was to establish the optimum values of these parameters for SIFDT-MS analyses. Particular focus was placed on diffusion losses and the distribution between the reagent ion $\mathrm{H}_{3} \mathrm{O}^{+}$and its hydrates $\mathrm{H}_{3} \mathrm{O}^{+}\left(\mathrm{H}_{2} \mathrm{O}\right)_{1,2,3}$ and how they are influenced by varying $E / N$ in the flow-drift tube reactor. Then SIFDTMS is shown to be a promising analytical method by analysing acetone and isoprene in exhaled breath as exemplars. Finally, the features of SIFDT-MS and SIFT-MS are compared and contrasted.

\section{EXPERIMENTAL SECTION}

Selected ion flow-drift tube, SIFDT, instrument. A new experimental SIFDT apparatus has been constructed as shown by the schematic arrangement in Figure 1. Its general structure is similar to the familiar SIFT-MS instruments. ${ }^{15}$ It consists of a gas discharge ion source that supplies a mixture of ions to a quadrupole mass filter that allows a current of ions at a selected mass-to-charge ratio, $\mathrm{m} / \mathrm{z}$, to be injected into a helium buffered flow-drift tube (a lead silicate coated resistive glass tube, length $14.5 \mathrm{~cm}$, internal diameter $1 \mathrm{~cm}, 14 \mathrm{M} \Omega$ resistance) manufactured by Photonis, Sturbridge, Massachusetts, USA. Application of a voltage between the ends of the flow-drift tube establishes a uniform electric field, $E$, along its axis. Variation of $E$ and the carrier gas number density, $N$, allows the reduced field strength $E / N$ to be varied at will. A gated electrostatic lens placed immediately before the Venturi inlet via which the helium carrier gas is introduced into the flow-drift tube allows the injected ion current to be switched on and off. Thus, the residence time of the ions in the flow-drift tube reactor can be determined at any value of $E / N$ by exploiting the Hadamard transform multiplexing technique. $\frac{18}{}$ The swarm of injected ions is transported along the flow-drift tube by a combination of carrier gas flow (speed component typically 10 
$\mathrm{m} / \mathrm{s}$ ) and by the $E$-field (drift speed component typically $>100 \mathrm{~m} / \mathrm{s}$ ). The pump driving the helium carrier gas flow is restricted (by throttling) to a speed of only $0.9 \mathrm{~L} / \mathrm{s}$ which is several times smaller than that required in SIFT-MS. $\frac{15}{}$ Sample gas is introduced at a controlled flow rate into the helium carrier gas and the contained water molecules and trace compounds react with the injected ions. The sample flow rate was adjusted by a needle valve and measured by a mass flow meter calibrated for air (Alicat Scientific, Inc. M-50SCCM-D) and the carrier gas flow rate was measured by a He-calibrated flow controller (Alicat Scientific, Inc. MC-5SLPM-D). The ion current arriving downstream at the sampling nose cone is measured using a picoammeter (pA; see Figure 1) and a fraction of ions is sampled by an orifice (0.5 mm diameter) into a quadrupole mass spectrometer/detection system that measures the count rates of both the reagent and product (analyte) ions. Note that electrical potentials of the ion source, injection quadrupole and associated ion lenses must be established with reference to the positive voltage $(<300 \mathrm{~V})$ applied to the upstream end of the flow-drift tube.

Experimental conditions. In order to describe and demonstrate the ion physics and chemistry that are the basis of the SIFTD-MS analytical method, several experiments were carried out as discussed in detail in the next section.

Data for ion residence time and loss of ions by diffusion were obtained for zero sample flow and for air samples saturated with water vapour at $300 \mathrm{~K}$ introduced at flow rates of 1.5 and $3 \mathrm{~mL} / \mathrm{min}$. Three flowdrift tube pressures of 1.5, 2.0 and 2.5 mbar were used (corresponding to He flow rates of 64, 94 and 124 $\mathrm{mL} / \mathrm{min}$ ) and the voltage difference across the drift tube was varied from 6 to $100 \mathrm{~V}$. The residence times of injected $\mathrm{H}_{3} \mathrm{O}^{+}$reagent ions and the ion currents measured at the downstream sampling nose cone were recorded as a function of $\mathrm{E} / \mathrm{N}$, the tube pressure and the sample flow rate (see the Results section).

In order to study hydration of $\mathrm{H}_{3} \mathrm{O}^{+}$ions, liquid water headspace was introduced into the flow-drift tube reactor at variable flow rates up to $5 \mathrm{~mL} / \mathrm{min}$ and data on the count rates of the $\mathrm{H}_{3} \mathrm{O}^{+}\left(\mathrm{H}_{2} \mathrm{O}\right)_{0,1,2,3}$ ions at $\mathrm{m} / \mathrm{z}$ 19, 37, 55, 73 were obtained for a range of drift tube voltages (25 to $100 \mathrm{~V}$ ). Similar experiments were carried out using headspace of a weak acetone solution in water $(1 \mu \mathrm{L}$ in $10 \mathrm{~mL})$ in order to study the formation of protonated acetone $\mathrm{CH}_{3} \mathrm{COCH}_{3} \mathrm{H}^{+}(\mathrm{m} / \mathrm{z} 59)$ and its hydrates $(\mathrm{m} / \mathrm{z} 77$ and 95$)$.

Finally, to demonstrate breath analysis by SIFDT-MS, a Nalophan bag $\frac{19}{19}$ was inflated with exhaled breath which was then introduced at a controlled flow rate into the flow-drift tube reactor and the reagent and product ion count rates were obtained as a function of the breath sample flow rate (1 to $5 \mathrm{~mL} / \mathrm{min}$ ) at $50 \mathrm{~V}$ and $100 \mathrm{~V}$ across the flow-drift tube at carrier gas pressure of $2 \mathrm{mbar}$ ( $E / \mathrm{N} 7 \mathrm{Td}$ and $14 \mathrm{Td}$; 1 Townsend, $\mathrm{Td},=10^{-17} \mathrm{~V} \mathrm{~cm}{ }^{2}$ ). Acetone in the breath sample was analysed using both $\mathrm{H}_{3} \mathrm{O}^{+}$(analyte ions as above) and $\mathrm{O}_{2}{ }^{+\bullet}$ (reagent ions $\mathrm{m} / \mathrm{z}$ 32; analyte ions $\mathrm{m} / \mathrm{z} 43$ and 58) and isoprene (analyte ions $\mathrm{m} / \mathrm{z} 67$ and 68). 


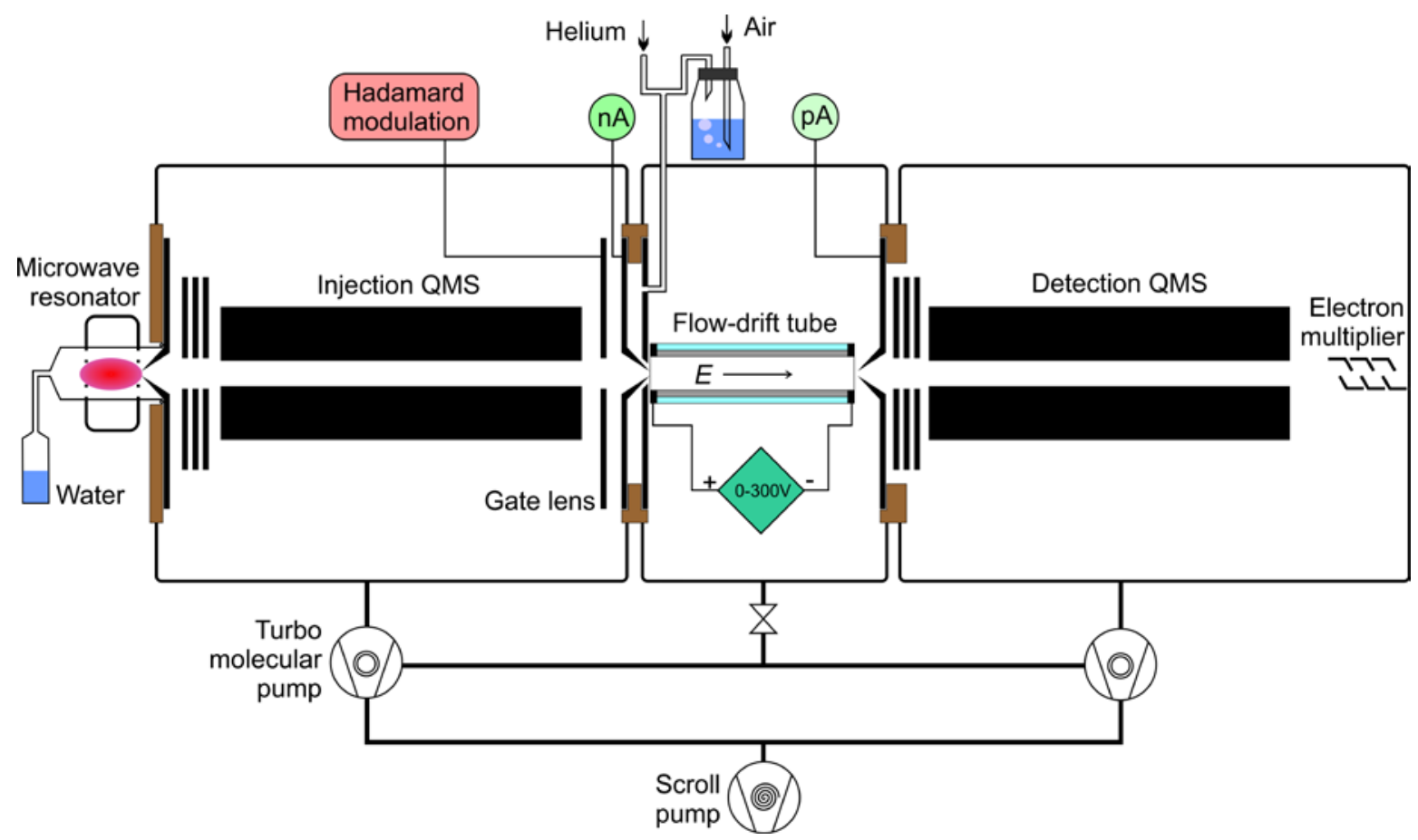

Figure 1. Schematic drawing of the selected ion flow-drift tube, SIFDT, apparatus developed and used for the present experiments. The gas sample introduction setup is represented in this example by a glass vial containing $10 \mathrm{ml}$ of liquid water through which dry synthetic air or laboratory air is introduced. Note that the speed of the helium carrier gas is reduced by a restrictive aperture between the flow-drift tube compartment and the scroll pump.

\section{RESULTS AND DISCUSSION}

Ion residence time and mobility. A fundamental parameter involved in the transport of ions in a flowdrift tube reactor and the kinetics of their reactions is the ion residence/reaction time, $t$. Example experimental measurements of $t$ as a function of $E / N$ obtained exploiting the Hadamard transform multiplexing are shown in Figure S1 (Supporting Information), where it can be seen how the predictable decrease of $t$ occurs with increasing $E / N$.

The ion velocity along the flow-drift tube axis can be calculated from its length $l$ as $v=l / t$. Experimental results at the three pressures 1.5, 2.0 and 2.5 mbar of the carrier gas, comprising helium with a small admixture of air (partial pressure $0.06 \mathrm{mbar}$ ), reveal the dependences of $v$ on $E$ as shown in Figure 2. It can be seen that this dependence is linear and can be described by the equation ${ }^{20}$

$$
v=v_{g}+v_{d}=v_{g}+\mu E
$$




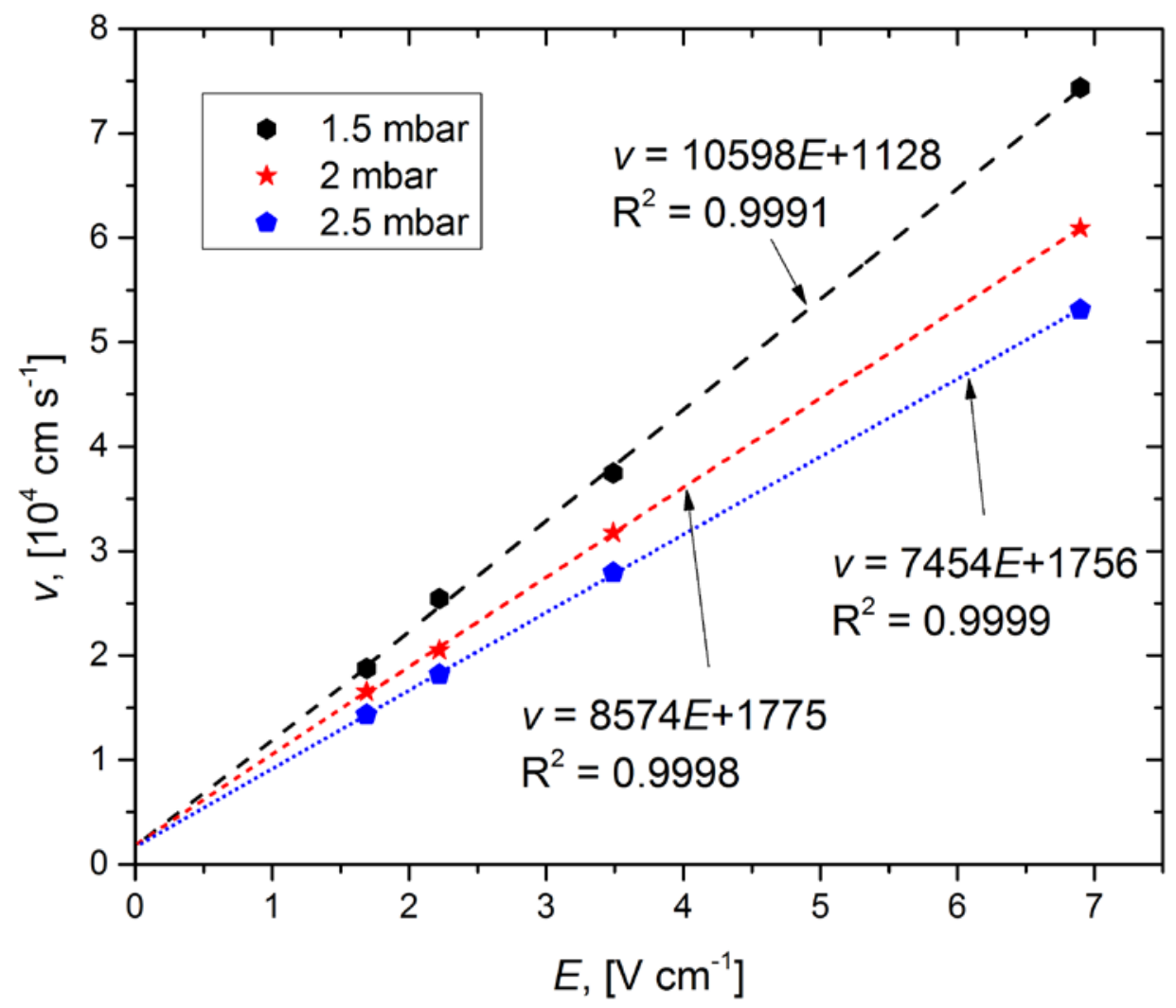

Figure 2. Dependence of the $\mathrm{H}_{3} \mathrm{O}^{+}$ion velocity, $v$, on the $E$-field strength at three helium pressures in the SIFDT. The linear fits with $\mathrm{R}^{2}$ values are shown for each pressure. Note the common intercept corresponding to, $v_{\mathrm{g}}$, the ion velocity due to the carrier gas flow only (zero $E$-field).

The constant term $v_{\mathrm{g}}$ corresponds to the velocity component due to gas flow only (averaged across the axial ion number density distribution) ${ }^{21}$ and the $\mu E$ term describes the drift velocity, $v_{\mathrm{d}}$, component due to the $E$-field in terms of the ion mobility $\mu=v_{\mathrm{d}} / E \underline{22}$. The mobility is conventionally normalised to standard temperature and pressure (STP: 1000 mbar and $273 \mathrm{~K}$ ) and quoted as the reduced ion mobility, $\mu_{0}$. Values of $\mu_{0}$ for $\mathrm{H}_{3} \mathrm{O}^{+}$ions in pure helium and for various $\mathrm{He}$ /air mixtures are obtained from the slopes of lines in Figure 2 and are listed in Table 1. Note that the $\mu_{0}$ obtained in pure He are in good agreement with the well-established literature value of $(21.5 \pm 1) \mathrm{cm}^{2} / \mathrm{V} \mathrm{s} . \stackrel{23, \underline{24}}{ }$ The reduced $\mu_{0}$ obtained for $\mathrm{H}_{3} \mathrm{O}^{+}$in helium with small fractions of $\mathrm{N}_{2}, \mathrm{O}_{2}, \mathrm{H}_{2} \mathrm{O}$ admixtures conforms to the predictions of Blanc's law for gas mixtures. $\frac{25}{}$ Data for ion residence times shown in detail in the Supporting Information (Figure S2) indicate that addition of $5 \%$ of air leads to decrease of mobility by a factor of 1.4. This corresponds to the change expected according to the well-established $\mu_{0}$ for $\mathrm{H}_{3} \mathrm{O}^{+}$in air of $2.7 \mathrm{~cm}^{2} / \mathrm{Vs} .{ }^{26}$ However, the number density of $\mathrm{H}_{2} \mathrm{O}$ molecules is some 30 times lower than that of $\left(\mathrm{N}_{2}+\mathrm{O}_{2}\right)$ molecules at the humidity of the samples and so the influence of the $\mathrm{H}_{2} \mathrm{O}$ molecules on $\mu_{0}$ is immeasurable and no effect of sample humidity on the ion residence time was observed within the time measurement resolution of about $5 \mu \mathrm{s}$. The corresponding small differences in $t$ at varying $E / N$ implied by these mobility measurements have to 
be considered when reaction times are required in SIFDT-MS, but they can be directly determined using Hadamard transform multiplexing (see Supporting Information, Figure S2).$\underline{18}$

Table 1. Reduced ion mobility, $\mu_{0}$, and the derived diffusion coefficient, $D_{0}$ (normalised to a pressure of 1 Torr; see text) of $\mathrm{H}_{3} \mathrm{O}^{+}$ions in pure helium at humid air sample flow rates of $0,1.5$ and $3 \mathrm{~mL} / \mathrm{s}$ and at three total He/air pressures of 1.5, 2.0 and 2.5 mbar. For comparison, the corresponding $D_{0}$ obtained from the dependence of ion current on $t$ are also given.

\begin{tabular}{|c|c|c|c|c|c|}
\hline \multicolumn{3}{|c|}{ He/air mixture } & \multicolumn{2}{|c|}{$\begin{array}{l}\text { Results from } t \\
\text { measurements }\end{array}$} & $\begin{array}{l}\text { Results from ion current } \\
\text { loss }\end{array}$ \\
\hline $\begin{array}{l}\text { Air flow, } \\
\mathrm{mL} / \mathrm{min}\end{array}$ & $\mathrm{p}, \mathrm{mbar}$ & $\begin{array}{l}\text { He flow, } \\
\mathrm{mL} / \mathrm{min}\end{array}$ & $\begin{array}{c}\mu_{0}, \\
\mathrm{~cm}^{2} / \mathrm{Vs}\end{array}$ & $D_{0}$, Torr $\cdot \mathrm{cm}^{2} / \mathrm{s}$ & $D_{0}$, Torr $\cdot \mathrm{cm}^{2} / \mathrm{s}$ \\
\hline 0 & 1.5 & 65 & 21.5 & 415 & 284 \\
\hline 0 & 2.0 & 94 & 20.9 & 403 & 307 \\
\hline 0 & 2.5 & 125 & 22.3 & 432 & 320 \\
\hline 1.5 & 1.5 & 63 & 18.6 & 360 & 260 \\
\hline 1.5 & 2.0 & 94 & 18.8 & 362 & 271 \\
\hline 1.5 & 2.5 & 121 & 19.6 & 380 & 298 \\
\hline 3 & 1.5 & 63 & 15.7 & 303 & 169 \\
\hline 3 & 2.0 & 94 & 16.9 & 327 & 207 \\
\hline 3 & 2.5 & 121 & 18.4 & 357 & 257 \\
\hline
\end{tabular}

Loss of ions by diffusion to the flow-drift tube wall. It is well understood that the diffusive loss of ions during their passage along the flow tube is the dominant process affecting the magnitude of ion signals detected downstream in SIFT-MS. ${ }^{25,27}$ Therefore, it is essential to characterise its importance in the SIFDT instrument by measuring the ion current arriving at the downstream sampling orifice disc, $i$, (see Figure 1) as the carrier gas pressure and the flow rate of the humid air sample and $E / N$ are varied. According to the well-established and often experimentally validated theory of fundamental mode axial diffusion in cylindrical tubes, $\underline{\underline{28}}$ lateral diffusive loss to the walls of the flow-drift tube is described by the simple equation:

$$
i=i_{0} \mathrm{e}^{-\frac{D t}{\Lambda^{2}}}=i_{0} \mathrm{e}^{-\frac{D_{0} p_{0}}{p} \frac{t}{\Lambda^{2}}}
$$

$i_{0}$ is the injected ion current, $t$ is the ion residence time and $\Lambda$ is a characteristic diffusion length that depends on the dimensions of the flow tube..$^{28}$ The diffusion coefficient, $D$, is inversely proportional to the carrier gas pressure, $p$, and is thus expressed as $D_{0} p_{0} / p$ where $D_{0}$ is the diffusion coefficient at a pressure $p_{0}=1$ Torr. The plots of the downstream current of $\mathrm{H}_{3} \mathrm{O}^{+}$ions, $i$, as a function of $t$ at the three pressures shown in Figure 3 demonstrates the exponential loss of ion signal in SIFDT as predicted by equation (2). Diffusion coefficients, $D_{0}$, calculated from the exponential time constants are given in the right column of Table 1. 


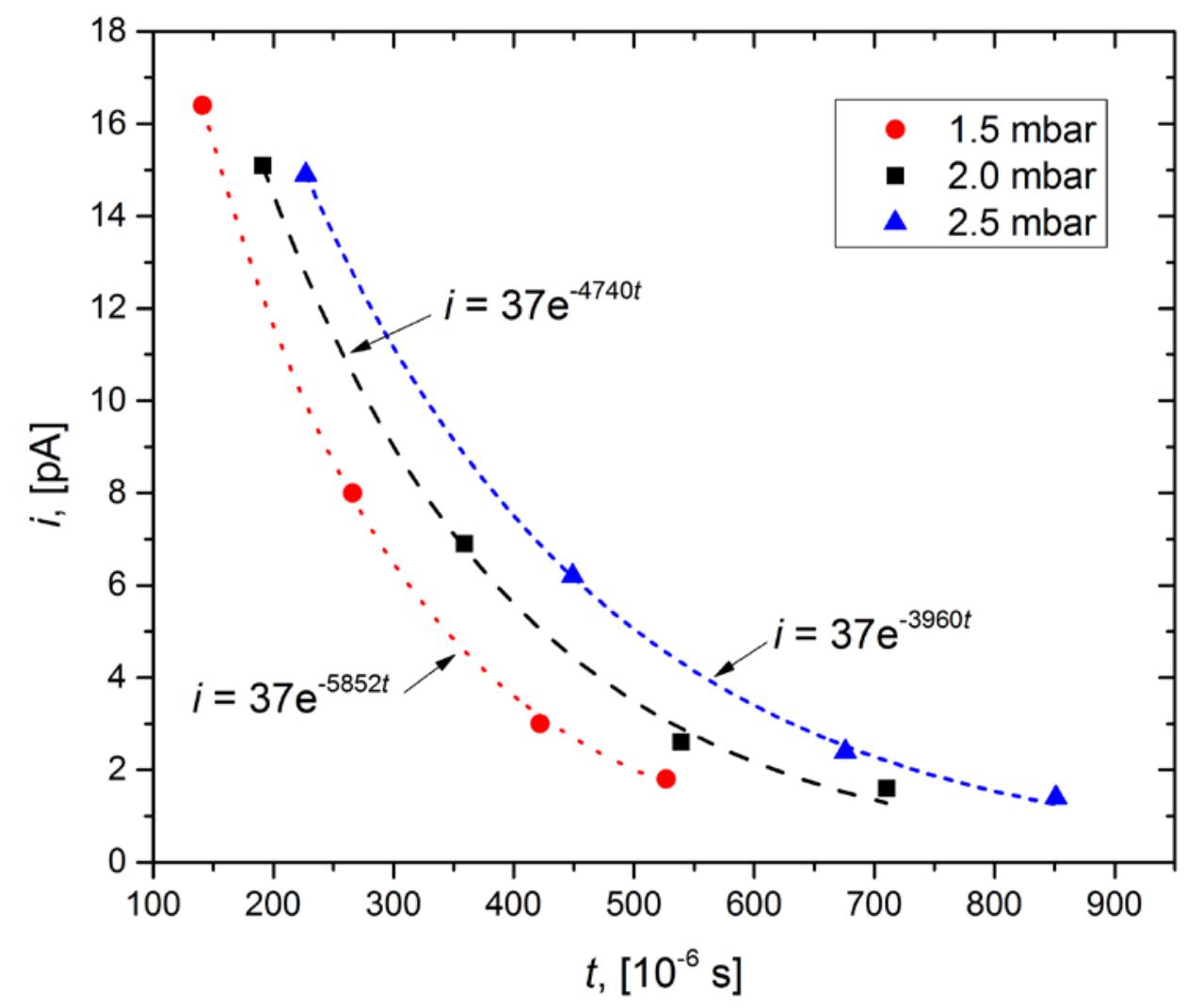

Figure 3. Plots of the $\mathrm{H}_{3} \mathrm{O}^{+}$ion current, $i$, in pA collected at the end of flow-drift tube at 3 different pressures of helium as a function of $t$ as varied by changing the voltage across the flow-drift tube between $6 \mathrm{~V}$ an $100 \mathrm{~V}$ ( $E / N$ values ranging from 2 to 18 Townsend, Td).

Note that there is a known connection between $D$ and $\mu$ known as the Einstein relation: $\underline{22}$

$$
D=\mu k_{b} T
$$

$k_{b}$ is Boltzmann constant and $T$ is the absolute temperature. Thus, the $D$ (and hence $D_{0}$ ) can be calculated from the acquired mobility of the ions under the conditions of the experiment and compared with the values obtained from the ion current measurements; see Table 1 . Note that all $D_{0}$ determined from the ion current loss are significantly lower than those predicted from the $\mu_{0}$ values. These differences clearly reveal that losses of ions to the wall are not occurring via fundamental mode diffusion along the whole length of the flow-drift tube and that initially an "ion beam" is formed in the upstream region that is not in close contact with the walls. The total injected ion currents, $I_{0}$, at each helium pressure derived from the intercepts of the exponential fits to the data in Figure 3 are $37 \mathrm{pA}$, being close to the current of $45 \mathrm{pA}$ that is measured by collecting the total injected ion current to the flow-drift tube walls. This difference may reflect the efficiency of injection of the $\mathrm{H}_{3} \mathrm{O}^{+}$ions into the helium carrier gas via the Venturi inlet at the operating pressure. The main significance of these results to ion-molecule kinetics studies and trace gas analysis is that they indicate that the residence time should be $<500 \mu$ s by using flow-drift tube voltages 
$>50 \mathrm{~V}$. This avoids major diffusive loss of ion signals and minimises differential diffusive loss of reagent and analyte ions. $\frac{25}{}$ As will be discussed in detail later, the analytical sensitivity of SIFDT-MS is proportional to both $t$ and $i$ and it is worthy of note that when the product $t \times i$ is expressed using data from Figure 3 for 2 mbar as a function of $t$ it is at a maximum around $210 \mu \mathrm{s}$.

Ion-molecule reactions in SIFDT-MS. A major objective of this work is to develop SIFDT-MS as an analytical technique that exploits chemical ionization by selected reagent ions (specifically $\mathrm{H}_{3} \mathrm{O}^{+}, \mathrm{NO}^{+}$ and $\mathrm{O}_{2}{ }^{+}$) in a flow-drift tube reactor. The essential difference between the envisaged SIFDT-MS and the established SIFT-MS technique is the presence of the variable $E$-field in the reaction zone. This provides an additional variable that can facilitate analyte ion identification. However, the influence of this E-field on the analytical ion chemistry must be recognized and understood.

Interaction energies. It is well understood from previous drift tube studies that the drift of reagent ions in an $E$-field increases both the ion/helium atom centre-of-mass gas energy, $E_{c}$, and the ion/reactant gas interaction energy, $E_{r}$. Increases in these energies can influence both the rates and products of ion molecule reactions and even result in fragmentation of the nascent product ions. $\underline{20} \underline{29} E_{r}$ can be calculated from the measured $v_{\mathrm{d}}$ and the masses of the drifting ion $m_{i}$, the helium carrier gas atom $m_{c}$, and the reactant gas molecule $m_{r} \underline{20,29}$ using the expression:

$$
E_{r}=\left[\left(m_{r} /\left(m_{i}+m_{r}\right)\right]\left(\frac{m_{i} v_{d}^{2}}{2}+\frac{m_{c} v_{d}^{2}}{2}\right)+\frac{3}{2} k_{B} T\right.
$$

Similarly, $E_{\mathrm{c}}$ is calculated using $m_{\mathrm{c}}$ instead of $m_{\mathrm{r}}$. The values of $E_{\mathrm{c}}\left(\mathrm{H}_{3} \mathrm{O}^{+}\right.$on $\left.\mathrm{He}\right)$ and $E_{\mathrm{r}}\left(\mathrm{H}_{3} \mathrm{O}^{+}\right.$on $\mathrm{H}_{2} \mathrm{O}$; see below) calculated as a function of $E / N$ under the conditions of the present experimental arrangement are given in Figure 4. As can be seen, $\mathrm{H}_{3} \mathrm{O}^{+}$collisions with the heavier $\mathrm{H}_{2} \mathrm{O}$ result in $E_{\mathrm{r}}>E_{\mathrm{c}}$. $\mathrm{But}_{3} \mathrm{H}_{3} \mathrm{O}^{+}$ collisions with the abundant $\mathrm{He}$ atoms are much more frequent than with $\mathrm{H}_{2} \mathrm{O}$ molecules and thus the equilibrium distribution of internal energy states of the $\mathrm{H}_{3} \mathrm{O}^{+}$reacting ions is defined by $E_{\mathrm{c}}$. Even at the modest values of $E / N$ adopted in these experiments, the equilibrium value of $E_{c}$ is $<0.6 \mathrm{eV}$ (see Figure 4). Most exothermic bimolecular reactions of ions with molecules occur at or near their collisional or gas kinetic rates and are not greatly influenced by small increases in interaction energies. ${ }^{20,30}$ However, this benign situation does not apply to those termolecular reactions that produce adduct ions or cluster ions in SIFDT-MS reactors, the rates of which usually decrease rapidly with increasing interaction energy $\underline{20}, 29, \underline{31}$, and then increases of $E_{\mathrm{c}}$ and $E_{\mathrm{r}}$ can have a profound effect, as we will show. 


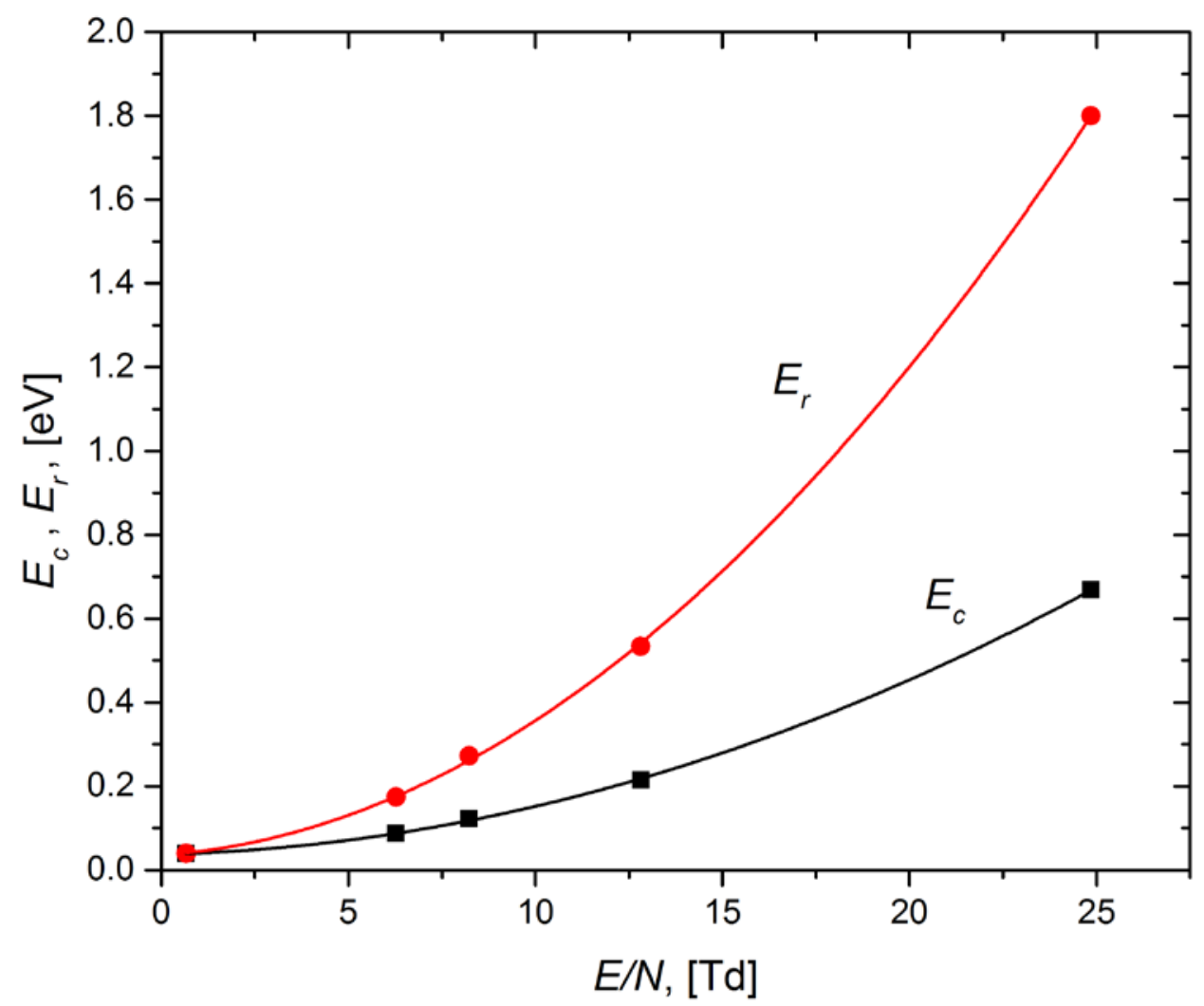

Figure 4. Dependencies of the mean $\mathrm{H}_{3} \mathrm{O}^{+} / \mathrm{He}$ atom centre-of-mass energy, $E_{c}$, and the mean $\mathrm{H}_{3} \mathrm{O}^{+} / \mathrm{H}_{2} \mathrm{O}$ molecule centre-of-mass energy, $E_{r}$, on the reduced field strength $E / N$. The data points are calculated using equation (4) from experimental ion drift velocity measurements.

Hydration of $\mathrm{H}_{3} \mathrm{O}^{+}$ions. The most significant termolecular reactions for SIFT-MS, and now also for SIFDT-MS analyses, are the sequence of association reactions of $\mathrm{H}_{3} \mathrm{O}^{+}$reagent ion with $\mathrm{H}_{2} \mathrm{O}$ molecules that results in $\mathrm{H}_{3} \mathrm{O}^{+}\left(\mathrm{H}_{2} \mathrm{O}\right)_{1,2,3}$ hydrated ions. The initial reaction of this sequence is:

$$
\mathrm{H}_{3} \mathrm{O}^{+}+\mathrm{H}_{2} \mathrm{O}+\mathrm{M} \rightarrow \mathrm{H}_{3} \mathrm{O}^{+}\left(\mathrm{H}_{2} \mathrm{O}\right)+\mathrm{M}
$$

$\mathrm{M}$ is a neutral third body that stabilizes the nascent $\left(\mathrm{H}_{3} \mathrm{O}^{+}\left(\mathrm{H}_{2} \mathrm{O}\right)\right)^{*}$ excited ion against spontaneous unimolecular dissociation back to the reactants. $\mathrm{M}$ is largely a helium atom and to a smaller extent the $\mathrm{N}_{2}$

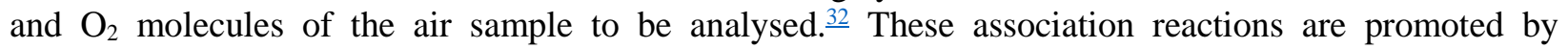
increasing the $\mathrm{H}_{2} \mathrm{O}$ and $\mathrm{M}$ number densities whilst their rate will decrease with increasing $E / N$ due to elevated $E_{c}$ and $E_{r}$. Further to this, increasing $E_{c}$ can promote collisional dissociation of the weakly-bound $\mathrm{H}_{3} \mathrm{O}^{+}\left(\mathrm{H}_{2} \mathrm{O}\right)_{1,2,3}$ hydrates. The binding energy of an $\mathrm{H}_{2} \mathrm{O}$ molecule to $\mathrm{H}_{3} \mathrm{O}^{+}$is 1.4 electron volts $(\mathrm{eV})$, that of the second $\mathrm{H}_{2} \mathrm{O}$ molecule is $0.87 \mathrm{eV}$ and for the third $\mathrm{H}_{2} \mathrm{O}$ molecule to form $\mathrm{H}_{3} \mathrm{O}^{+}\left(\mathrm{H}_{2} \mathrm{O}\right)_{3}$ ions is 0.75 $\mathrm{eV} . \underline{33}$ Experimental results on observed fractions of the hydrated ions are shown in Figure 5 where it can be seen that the $\mathrm{H}_{3} \mathrm{O}^{+}\left(\mathrm{H}_{2} \mathrm{O}\right)_{2}$ and $\mathrm{H}_{3} \mathrm{O}^{+}\left(\mathrm{H}_{2} \mathrm{O}\right)_{3}$ ions disappear at $E / N>14$ Td for both sample flow rates. The increase in the fraction of the $\mathrm{H}_{3} \mathrm{O}^{+}$primary ions with increasing $E / N$ is due to decreasing $t$ and the decreasing rate coefficient of reaction (5). 

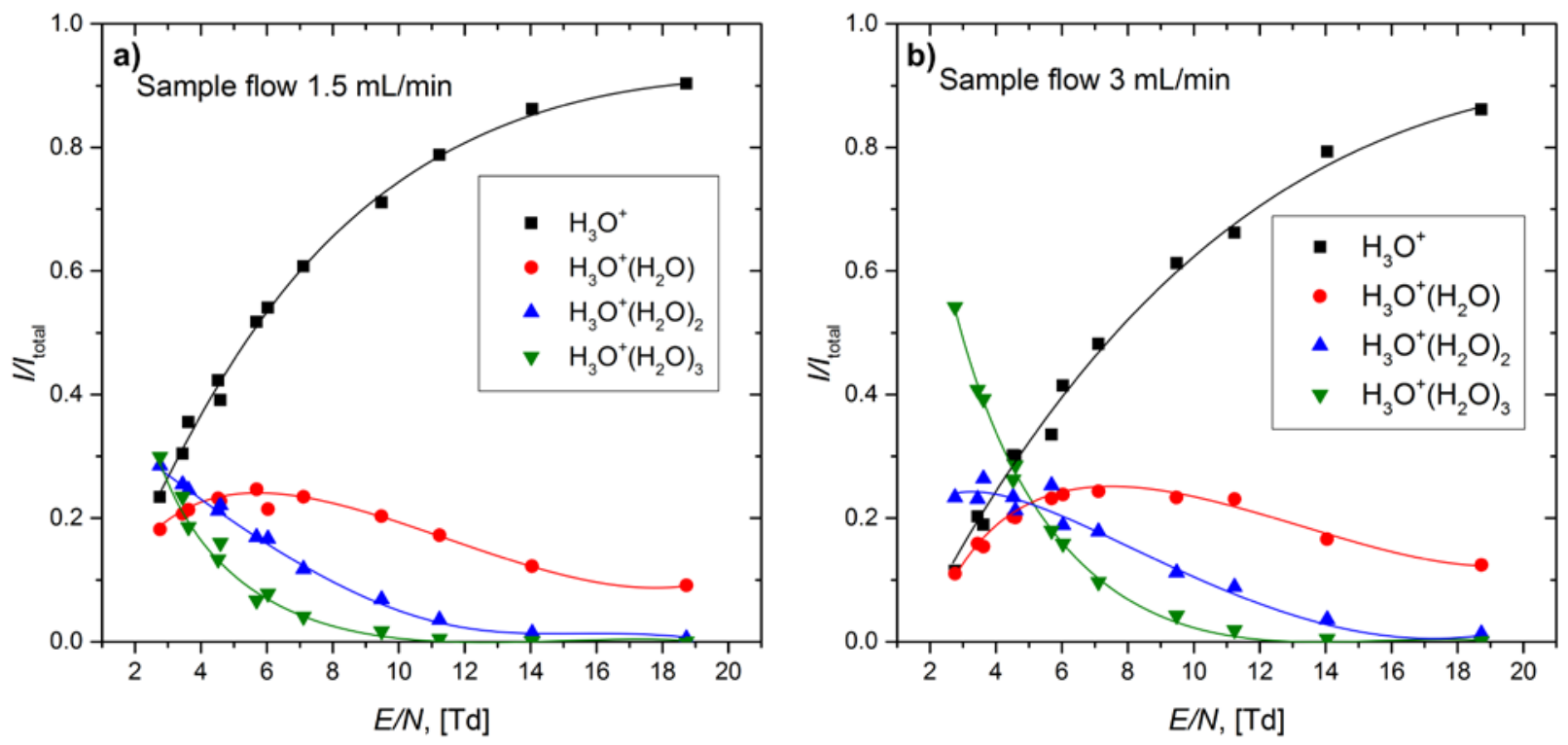

Figure 5. Variation of the relative count rates of the $\mathrm{H}_{3} \mathrm{O}^{+}\left(\mathrm{H}_{2} \mathrm{O}\right)_{0,1,2,3}$ ions as a function of $E / N$ in the flowdrift tube when samples of humid air at the two flow rates indicated ( $a$ and b) are introduced into the helium carrier gas, where $I$ is a measured count rate of selected ion and $I_{\text {total }}$ is sum of the all $\mathrm{H}_{3} \mathrm{O}^{+}\left(\mathrm{H}_{2} \mathrm{O}\right)_{0,1,2,3}$ ions count rates.

It is important to confirm that the reverse of reaction (5) ${ }^{34}$ does not occur for this range of $E / N$. To verify this, the dependencies of the count rates of $\mathrm{H}_{3} \mathrm{O}^{+}$and its hydrates were obtained over a wide range of the water concentration in the flow-drift tube (see Figure 6). The results indicate that $\mathrm{H}_{3} \mathrm{O}^{+}$ions exponentially decay by two orders-of-magnitude and to near zero values. The fraction of hydrated ions at the end of the flow-drift tube reactor can thus be expressed as $\underline{35}$ :

$$
\frac{I_{0}-I_{19}}{I_{0}}=1-\exp \left(-k_{3} t\left[\mathrm{H}_{2} \mathrm{O}\right][\mathrm{He}]\right)=1-\exp \left(-k_{2 e f f} t\left[\mathrm{H}_{2} \mathrm{O}\right]\right)
$$

$I_{0}\left(=\left[\mathrm{H}_{3} \mathrm{O}^{+}\right]_{0}\right)$ is the count rate of $\mathrm{H}_{3} \mathrm{O}^{+}$in the absence of $\mathrm{H}_{2} \mathrm{O}$ molecules and $I_{19}\left(=\left[\mathrm{H}_{3} \mathrm{O}^{+}\right]\right)$is this count rate in the presence of $\mathrm{H}_{2} \mathrm{O}$ molecules at a number density of $\left[\mathrm{H}_{2} \mathrm{O}\right]$ and helium atoms at a number density [He]. $k_{3}$ is the termolecular rate coefficient for reaction (5) and $k_{2 \mathrm{eff}}=k_{3}[\mathrm{He}]$ is the corresponding effective bimolecular rate coefficient. The decrease of $\mathrm{H}_{3} \mathrm{O}^{+}$to about $2 \%$ of $I_{0}$ indicates that the reverse reaction (5) can be neglected at $E / N \leq 14 \mathrm{Td}$. 


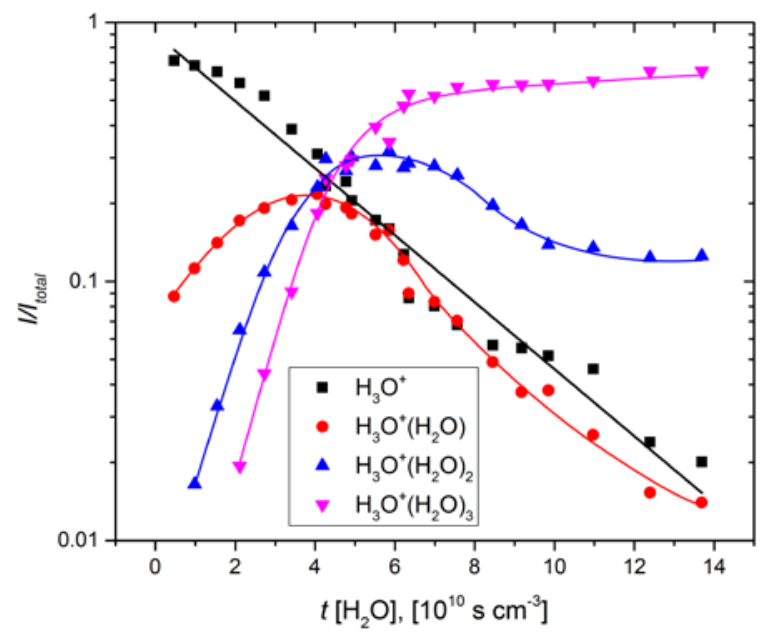

Figure 6. Distributions of the relative count rates of $\mathrm{H}_{3} \mathrm{O}^{+}$ion and its hydrates plotted against the product of the ion residence/reaction time, $t$, and water molecule number density in the flow-drift tube reactor at $E / N 14 T d$ (see equation (6)).

Rate coefficient for $\mathrm{H}_{3} \mathrm{O}^{+}$hydration reactions. The value of $k_{3}$ for reaction (5) under thermalized conditions at $300 \mathrm{~K}$ with helium atoms as the third body $\mathrm{M}$ is well established and it is routinely used in SIFT-MS to determine the absolute humidity of the sample gas to be analysed. $\frac{36}{6}$ But as $E / N$ is increased such that $E_{\mathrm{c}}$ and $E_{\mathrm{r}}$ increase above their thermal values (both $0.026 \mathrm{eV}$ at $300 \mathrm{~K}$ ) it is expected that $k_{2 \text { eff }}$ will decrease. To our knowledge, drift tube studies of the association reaction of $\mathrm{H}_{3} \mathrm{O}^{+}$with $\mathrm{H}_{2} \mathrm{O}$ have not been carried out previously even though this reaction occurs at suprathermal energies in PTR-MS analytical reactors. ${ }^{11}$ Thus, in order to fully understand SIFDT ion chemistry and for reliable SIFDT-MS analyses, $k_{3}$ must be experimentally determined over a range of $E / N$. This is achieved by measuring the $\mathrm{H}_{3} \mathrm{O}^{+}$count rate at the downstream detection system as the water molecule number density $\left[\mathrm{H}_{2} \mathrm{O}\right]$ in the flow-drift reactor is varied by changing the flow rate and humidity of the air sample introduced into the helium carrier gas. Samples at three humidity values were used, viz. dry synthetic air, dry synthetic air bubbling through liquid water, and relatively humid laboratory air bubbling through liquid water; all components held at room temperature. $\left[\mathrm{H}_{2} \mathrm{O}\right]$ was calculated using the known thermal values of termolecular rate coefficients for reaction (5) at $300 \mathrm{~K}$ from for the two third bodies He $\left(k_{3}=7.2 \times 10^{-28}\right.$ $\left.\mathrm{cm}^{6} \mathrm{~s}^{-1}\right)$ and $\mathrm{N}_{2}\left(k_{3 \mathrm{~N}}=3.4 \times 10^{-27} \mathrm{~cm}^{6} \mathrm{~s}^{-1}\right)$. Thus, for these three different samples the $\left[\mathrm{H}_{2} \mathrm{O}\right]$ values were respectively $8.5 \times 10^{12} \mathrm{~cm}^{-3}, 2.8 \times 10^{13} \mathrm{~cm}^{-3}$ and $6.4 \times 10^{13} \mathrm{~cm}^{-3}$ at a fixed sample flow rate of $40 \mathrm{~mL} / \mathrm{min}$ and a helium carrier gas flow rate of $1000 \mathrm{~mL} / \mathrm{min}$ (using a pumping speed 10 times greater than in all the other present experiments in order to achieve measurements at low $E / N=0.7$; further details are given in ${ }^{37}$ ). These $\left[\mathrm{H}_{2} \mathrm{O}\right]$ values translate to sample absolute humidities of $0.29 \%, 0.97 \%$ and $2.2 \%$. $k_{2 \text { eff }}$ has been determined using equation (6) and its variations with $E / N$ and $E_{\mathrm{c}}$ and $E_{\mathrm{r}}$ are shown in Table 2. 
Table 2 Values of $k_{2 \text { eff }}$ experimentally obtained in SIFDT for several reduced field strengths $E / N$ (Td) in carrier gas comprising $96 \% \mathrm{He}$ and $4 \%$ air/water vapour mixture at a total pressure of 2 mbar and temperature of $300 \mathrm{~K}$. The corresponding values of the mean ion/carrier gas atom centre-of-mass energy $E_{c}$, the mean ion/reactant gas centre-of-mass energy $E_{r}$ are also given in electron volts $(\mathrm{eV})$.

\begin{tabular}{cccc}
\hline $\begin{array}{l}E / N, \\
\mathrm{Td}\end{array}$ & $\begin{array}{l}E_{c}, \\
\mathrm{eV}\end{array}$ & $\begin{array}{l}E_{r}, \\
\mathrm{eV}\end{array}$ & $\begin{array}{l}k_{2 e f f}, \\
10^{-11} \mathrm{~cm}^{3} \mathrm{~s}^{-1}\end{array}$ \\
\hline 0.7 & 0.04 & 0.04 & 6.4 \\
6.3 & 0.09 & 0.17 & 4.9 \\
8.2 & 0.12 & 0.27 & 4.2 \\
12.8 & 0.22 & 0.53 & 1.9 \\
24.8 & 0.67 & 1.80 & 0.7 \\
\hline
\end{tabular}

Note in Table 2 the consistent decrease in $k_{2 \text { eff }}$ with increasing $E / N, E_{c}$ and $E_{r}$, largely due to kinetic and internal excitation of the reacting $\mathrm{H}_{3} \mathrm{O}^{+}$ions. These data indicate that $k_{2 e f f}$ approximately varies as $E_{\mathrm{c}}{ }^{-1}$ and $E_{\mathrm{r}}^{-0.5}$, whereas termolecular association reactions involving polyatomic ion and neutral reactants are theoretically predicted to decrease much more rapidly with true temperature, $T$, as $T^{-3} \underline{20}$. This clear difference indicates that an increase of $E / N$, and the concomitant small increases in $E_{c}$ and $E_{r}$, are relatively inefficient in exciting the vibrational and rotational modes of both the reactant ion $\mathrm{H}_{3} \mathrm{O}^{+}$and the reactant molecule $\mathrm{H}_{2} \mathrm{O}$ compared to an increase of the equilibrium temperatures of these species (see $\underline{20}$ for details). The $k_{2 \text { eff }}$ values are now defined at different $E / N$ for the particular SIFDT-MS conditions and can be used to measure sample humidity, as reprised in the next short section.

Determination of water vapour concentration (sample humidity). A unique aspect of SIFT-MS analyses is the ability to determine the absolute humidity of the sample being analysed (typically at the few \% by volume level) and to simultaneously quantify the trace gases in the sample (typically at the parts-perbillion by volume, ppbv, level). This valuable aspect of SIFT-MS analysis and how it is exploited to routinely validate breath or liquid headspace samples has been described in detail previously. $\frac{36}{\text { Similarly, }}$

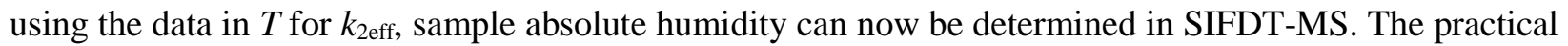
approach to this is to obtain the initial value of the $\mathrm{H}_{3} \mathrm{O}^{+}$signal $I_{0}\left(=\left[\mathrm{H}_{3} \mathrm{O}^{+}\right]_{0}\right)$ as the sum of the count rates of the $\mathrm{H}_{3} \mathrm{O}^{+}\left(\mathrm{H}_{2} \mathrm{O}\right)_{0,1,2,3}$ ions and to relate this sum to the observed $\left[\mathrm{H}_{3} \mathrm{O}^{+}\right]$count rate $I_{19}$ and to calculate $\left[\mathrm{H}_{2} \mathrm{O}\right]$ using equation (6).

Quantification of volatile compounds in air by SIFDT-MS. The underlying and controlling physics of the new SIFDT apparatus and the influence of an increasing $E / N$ on the $\mathrm{H}_{3} \mathrm{O}^{+}$association reactions with $\mathrm{H}_{2} \mathrm{O}$ molecules and the fractional distribution of product $\mathrm{H}_{3} \mathrm{O}^{+}\left(\mathrm{H}_{2} \mathrm{O}\right)_{1,2,3}$ hydrates is now understood. The fundamental difference between SIFT-MS and the SIFDT-MS analytical system is that in the latter the different reagent ionic species present (i.e. $\mathrm{H}_{3} \mathrm{O}^{+}$and $\mathrm{H}_{3} \mathrm{O}^{+}\left(\mathrm{H}_{2} \mathrm{O}\right)_{1,2,3}$ ) drift at different speeds along the flow-drift tube and thus have different reaction times. The well-established equation ${ }^{25}$ used in SIFT-MS to quantify the absolute number density of reagent molecules, [M], in the reactor tube must be modified to account for this and is now:

$$
[\mathrm{M}]=\frac{I_{p 1}+I_{p 2}+\ldots}{\left(I_{19}+\frac{I_{37}}{2}+\frac{I_{55}}{2}+\frac{I_{73}}{2}\right) k_{19} t_{19}+\frac{I_{37}}{2} k_{37} t_{37}+\frac{I_{55}}{2} k_{55} t_{55}+\frac{I_{73}}{2} k_{73} t_{73}}
$$


$I_{\mathrm{p} 1}, I_{\mathrm{p} 2}$, etc. are the count rates of all the product ions. $I_{19}, I_{37}$, etc. are the count rates of the precursor ions (e.g. $\mathrm{H}_{3} \mathrm{O}^{+}, \mathrm{H}_{3} \mathrm{O}^{+}\left(\mathrm{H}_{2} \mathrm{O}\right)$ etc.) corrected for the mass discrimination ${ }^{15}$ of the detection mass spectrometer as established by experiments that correlate ion pA currents for specific $\mathrm{m} / \mathrm{z}$ value ions at the downstream sampling mass spectrometer disc (see Figure 1) with ion count rates determined by the mass spectrometer detection system. ${ }^{25} k_{19}, k_{37}$ etc. are the rate coefficients for the reactions of the reagent ions with $M$. The values of $k$ can be obtained experimentally and their variation with $E / N$ for drift speeds up to $930 \mathrm{~m} / \mathrm{s}$ is typically less than $14 \%$. $\frac{30}{19} t_{19} t_{37}, t_{55}$ and $t_{73}$ are the residence/reaction times of the individual reagent ion species in the flow-drift tube that are directly measured in SIFDT-MS. The factors $1 / 2$ approximate the fact that the average currents of hydrated ions traversing the flow-drift tube is lower than that corresponding to the count rates observed downstream. ${ }^{25}$ The concentration of $\mathrm{M}$ in the sample being analysed can then be determined from the known sample gas dilution in the helium carrier/buffer gas, as described for SIFTMS in previous papers. $., 17, \underline{25}$ Uncertainty of the quantification can be estimated as $\pm 20 \%$ by error analysis from the combined uncertainties of the gas flow rates and all parameters in equation (7). Validation of SIFDT-MS analyses for various analyte neutral compounds will require much experimentation along the same lines as carried out to establish SIFT-MS. ${ }^{17, \underline{38}}$ As a beginning, a simple case study has been carried out to characterise the ion chemistry involved in analyses of acetone vapour in humid air by SIFDT-MS.

Hydration of protonated acetone when analysing humid air. The headspace of an aqueous solution of acetone at a dilution sufficient to realize an acetone vapour concentration of approximately 30 parts-permillion by volume, ppmv, was introduced into the $\mathrm{H}_{3} \mathrm{O}^{+}$/helium carrier gas swarm as described in the Experimental section. The primary bimolecular reaction of $\mathrm{H}_{3} \mathrm{O}^{+}$with the acetone molecules (M) results in the production of protonated acetone molecules, $\mathrm{MH}^{+}$, and the termolecular reactions of $\mathrm{H}_{3} \mathrm{O}^{+}$with $\mathrm{H}_{2} \mathrm{O}$ molecules produces $\mathrm{H}_{3} \mathrm{O}^{+}\left(\mathrm{H}_{2} \mathrm{O}\right)_{1,2,3}$ ions. Secondary association reactions of $\mathrm{MH}^{+}$ions with $\mathrm{H}_{2} \mathrm{O}$ molecules and switching reactions of the $\mathrm{H}_{3} \mathrm{O}^{+}\left(\mathrm{H}_{2} \mathrm{O}\right)_{1,2,3}$ ions with $\mathrm{M}$ molecules results in hydrated protonated acetone ions, $\mathrm{MH}^{+}\left(\mathrm{H}_{2} \mathrm{O}\right)_{1.2}$.

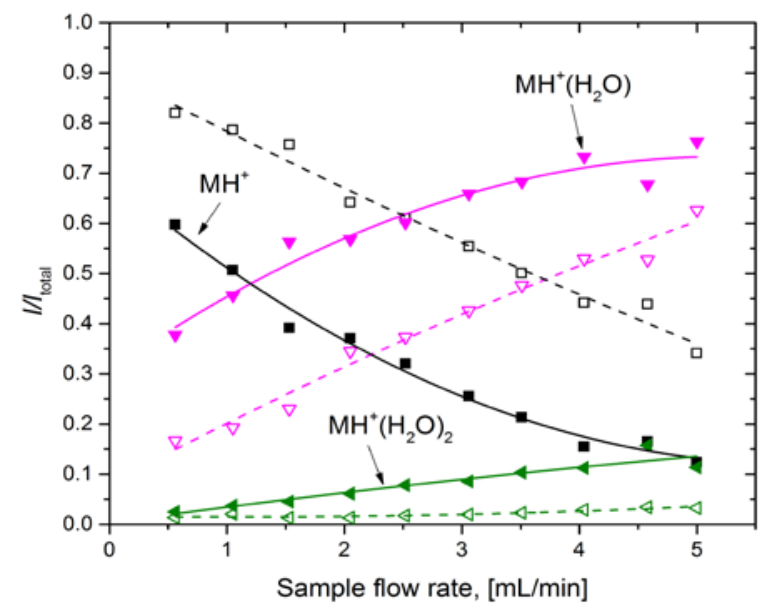

Figure 7. Plots of the relative count rates of protonated acetone (designated $\mathrm{MH}^{+}$) and its mono- and dihydrates (designated $\mathrm{MH}^{+}\left(\mathrm{H}_{2} \mathrm{O}\right)_{1,2}$ ) as a function of the acetone/humid air mixture flow rate at two $E / N$ values of $7 \mathrm{Td}$ (filled symbols) and $14 \mathrm{Td}$ (open symbols)

Relative count rates of the analyte ion $\mathrm{MH}^{+}$and its hydrates $\mathrm{MH}^{+}\left(\mathrm{H}_{2} \mathrm{O}\right)_{1,2}$, as a function of the acetone/humid air sample flow rate at two $E / N$ values are shown in Figure 7. Predictably, it can be seen that the fractions of the $\mathrm{MH}^{+}\left(\mathrm{H}_{2} \mathrm{O}\right)_{1,2}$ ions increase with sample flow rate and are lower at the higher $E / N$ 
value. It is important to note that at both $E / N$ the count rates of hydrated protonated acetone (at $\mathrm{m} / \mathrm{z} 77$ ) are comparable to the count rates of protonated acetone molecules (at $\mathrm{m} / \mathrm{z} 59$ ) and they reach identical values for sample flow rates of about $1 \mathrm{~mL} / \mathrm{min}$ at $7 \mathrm{Td}$ and of about $4 \mathrm{~mL} / \mathrm{min}$ at $14 \mathrm{Td}$. On the basis of bulk of the experience with SIFT-MS, it is judged that the range of sample flow rates for analyses of humid air should be 1 to $5 \mathrm{~mL} / \mathrm{min}$, since at higher flow rates the hydration of ions will dominate the ion chemistry.

Examples of breath analysis using $\mathrm{H}_{3} \mathrm{O}^{+}$and $\mathrm{O}_{2}{ }^{+\bullet}$ reagent ions. As described in the Experimental section, a sample of breath collected into a Nalophan bag was used to demonstrate the analytical use of SIFDT-MS. Mass spectra obtained using the $\mathrm{H}_{3} \mathrm{O}^{+}$and $\mathrm{O}_{2}{ }^{+\cdot}$ reagent ions for flow rate of $3 \mathrm{~mL} / \mathrm{min}$ and $E / N 14 \mathrm{Td}$ corresponding to a reagent ion residence time of $230 \mu \mathrm{s}$ are shown in Figure S3 of the Supporting Information where it can be seen that the count rate of the reagent $\mathrm{H}_{3} \mathrm{O}^{+}$ion is 400000 counts per second $(\mathrm{c} / \mathrm{s})$ and that of $\mathrm{O}_{2}{ }^{+\cdot}$ reagent ion is $500000 \mathrm{c} / \mathrm{s}$. The appearance of the spectra is very similar to traditional SIFT-MS spectra and count rates of product analyte ions for this particular breath acetone analysis are about $150 \mathrm{c} / \mathrm{s}$ at $\mathrm{m} / \mathrm{z}$ 59, $77\left(\mathrm{H}_{3} \mathrm{O}^{+}\right), 43$ and $58\left(\mathrm{O}_{2}{ }^{+*}\right)$. Adopting the appropriate reaction times, $t$, at the two $E / N$ values (see Figure S2, Supporting Information) and the rate coefficients for the reactions of the $\mathrm{H}_{3} \mathrm{O}^{+}\left(\mathrm{H}_{2} \mathrm{O}\right)_{0,1,2,3}$ and $\mathrm{O}_{2}{ }^{+\cdot}$ ions with acetone molecules ${ }^{39}$, the number density of neutral acetone molecules in helium carrier gas [M] were calculated at the different sample flow rates using equation (7). Note that the calculation for $\mathrm{O}_{2}{ }^{+\bullet}$ is simpler using just a single term in the denominator of the fraction. The results are shown for the two $E / N$ values in Figure 8a.
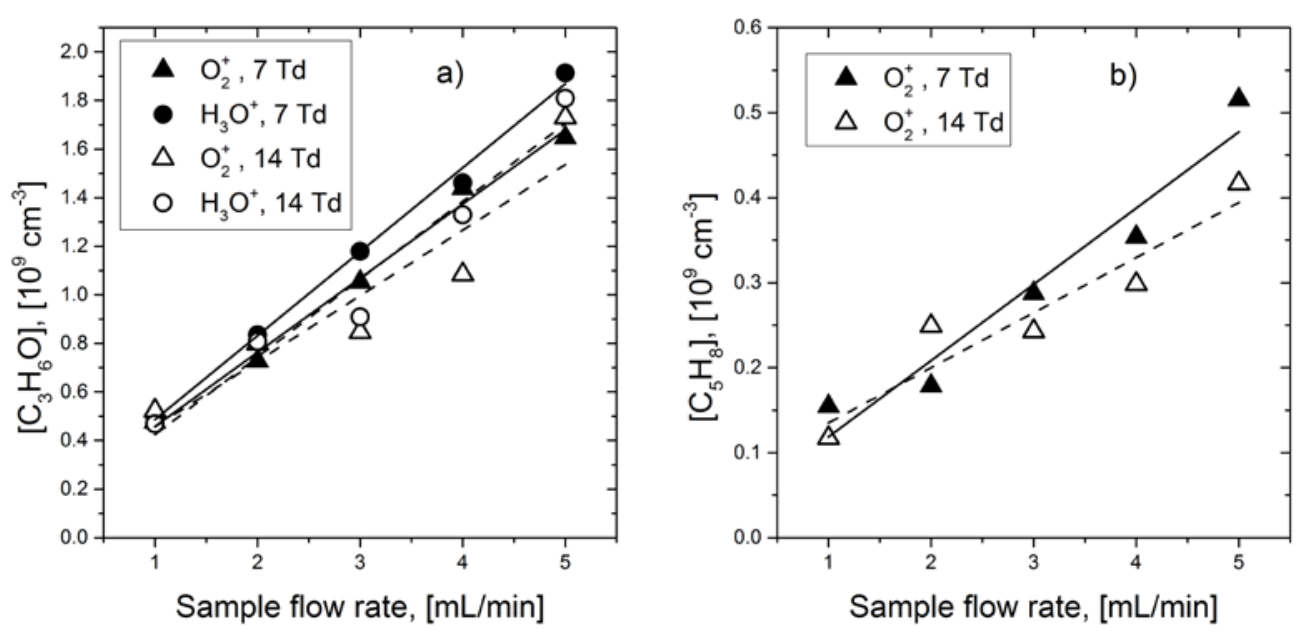

Figure 8. a) Acetone molecule number density in the flow-drift tube reactor $[\mathrm{M}]$ calculated using equation (7) when humid exhaled breath sample is introduced at a variable sample flow rate into SIFDTMS using both $\mathrm{H}_{3} \mathrm{O}^{+}$and $\mathrm{O}_{2}{ }^{+}$reagent ions at the two values of $E / N$ indicated. b) Isoprene molecule number density obtained in the same experiment using the $\mathrm{O}_{2}{ }^{+}$reagent ions.

The derived mean absolute concentrations of the acetone in the breath sample is $542 \pm 108$ ppbv at $7 \mathrm{Td}$ and $503 \pm 101 \mathrm{ppbv}$ at $14 \mathrm{Td}$ using $\mathrm{H}_{3} \mathrm{O}^{+}$reagent ions and $497 \pm 99$ ppbv and $444 \pm 89$ ppbv respectively using $\mathrm{O}_{2}{ }^{+\bullet}$ reagent ions. Similarly, the isoprene concentration in the breath sample is $140 \pm 28 \mathrm{ppbv}$ at $7 \mathrm{Td}$ and $110 \pm 22 \mathrm{ppbv}$ at $14 \mathrm{Td}$. The concentrations agree with parallel SIFT-MS analyses of the same bag sample that gave $400 \pm 80 \mathrm{ppbv}$ for acetone and $150 \pm 30$ for isoprene. The mean SIFDT-MS results for acetone appear to be about $25 \%$ higher whilst the isoprene concentrations are in better agreement. We 
considered this to be satisfactory at this early development stage of SIFDT-MS. Further detailed checks will be carried out, which will include the use of calibrated mixtures, striving for greater analytical precision and accuracy for the analysis of exhaled breath and other biogenic media.

\section{Concluding remarks}

The major objective of this work was to develop an analytical technique that extends SIFT-MS by including a drift tube component to establish an embedded $E$-field along the axis of the reactor, whilst retaining the unique versatile features that facilitate real time analysis as in SIFT-MS. Thus, SIFDT-MS is introduced. A major advance compared to SIFT-MS is that the speed of ions through the reaction zone can be achieved using the adjustable $E$-field, which allows the suppression of ion diffusion losses even at very low carrier gas flow speeds corresponding to helium carrier gas and sample gas flow rates more than 7 times lower than those used in Profile 3 SIFT-MS instruments. Thus, a less powerful vacuum pump can be used to maintain the gas flow along the ion-chemical reactor and a smaller helium carrier gas pressure reservoir is needed, which facilitates production of smaller and more versatile transportable instruments. Furthermore, smaller sample flow rates can be used for analysis, which is a distinct advantage when, for example, liquid headspace is to be analysed.

The simplicity of construction of the SIFDT-MS instrument is due to the use of a resistive glass flow-drift tube element and by adopting the Hadamard transform multiplexing for direct reaction time measurement, which is another improvement on SIFT-MS in which the reaction times are fixed and calculated indirectly from the gas pressure and flow rate. The presence of the $E$-field results in an increase of the kinetic and internal energies of the ions that influence hydrated ion formation and the initial studies confirmed that variation of $E / N$ modifies the count rates of hydrated product ions relatively to the primary product ions. The use of low $E / N$ values somewhat inhibits reagent and analyte ion hydration without significantly modifying the bimolecular ion chemistry, thus promising more accurate analyses. However, it is worthy of note that increasing $E / N$ to higher values $(>20 \mathrm{Td}$ ) can promote controlled collisional dissociation of ions and this might ultimately allow isobaric ions to be distinguished, a technique well known in MS-MS methods.

The preliminary breath analyses data presented in this announcement of SIFDT-MS are intended only to demonstrate the potential of this new analytical method. Clearly, it is anticipated that by further work a valuable, smaller, less costly instrument will be added to the analytical armoury that will fill the need for real time breath analysis in the clinic and factory environs, etc. and in other areas where trace gas analysis of ambient air is valuable. 
The optimal working parameters for SIFDT-MS, identified by the present experiments, are summarised in Table 3 and compared with the corresponding parameters used in Profile 3 SIFT-MS. $\underline{15}^{15}$ This reveals the enhanced and attractive features of this SIFDT-MS analytical method.

Table 3. Comparison of the optimal operating parameters for the new SIFDT-MS instrument and the Profile 3 SIFT-MS instrument

\begin{tabular}{lll}
\hline Feature & SIFDT-MS & SIFT-MS \\
\hline$E / N$ & $7-14 \mathrm{Td}$ & 0 \\
flow/drift tube pressure & $2 \mathrm{mbar}$ & $1.3 \mathrm{mbar}$ \\
He flow rate & $<100 \mathrm{~mL} / \mathrm{min}$ & $500 \mathrm{~mL} / \mathrm{min}$ \\
sample flow rate & $<4 \mathrm{~mL} / \mathrm{min}$ & $20-30 \mathrm{~mL} / \mathrm{min}$ \\
pumping speed & $<1 \mathrm{~L} / \mathrm{s}$ & $7 \mathrm{~L} / \mathrm{s}$ \\
reaction time & variable (accurately measured) & fixed \\
regent ion count rate & up to $1000000 \mathrm{c} / \mathrm{s}$ & up to $1000000 \mathrm{c} / \mathrm{s}$ \\
limit od detection & $<1 \mathrm{ppbv}$ & $<1 \mathrm{ppbv}$ \\
reaction time & variable $($ accurately measured) & fixed \\
ion hydration & variable by $E / N$ for a given sample & constant for a given \\
& flow rate & sample flow rate \\
\hline
\end{tabular}

\section{ASSOCIATED CONTENT}

\section{Supporting Information}

Additional information as noted in the text. The Supporting Information is available free of charge on the ACS Publications website.

\section{AUTHOR INFORMATION}

Corresponding Author: *P. Španěl. E-mail: spanel@jh-inst.cas.cz

Notes The authors declare no competing financial interest.

\section{ACKNOWLEDGMENTS}

We gratefully acknowledge funding by The Czech Science Foundation GACR project 13-28882S.

\section{References}

(1) Smith, D.; Španěl, P. Ambient analysis of trace compounds in gaseous media by SIFT-MS. Analyst 2011, 136. 2009-2032.

(2) Španěl, P.; Smith, D. Progress in SIFT-MS: Breath analysis and other applications. Mass Spectrom. Rev. 2011, 30. 236-267.

(3) Muller, M.; Mikoviny, T.; Feil, S.; Haidacher, S.; Hanel, G.; Hartungen, E.; Jordan, A.; Mark, L.; Mutschlechner, P.; Schottkowsky, R.; Sulzer, P.; Crawford, J.H.; Wisthaler, A. A compact PTR-ToF-MS instrument for airborne measurements of volatile organic compounds at high spatiotemporal resolution. Atmos. Meas. Tech. 2014, 7. 3763-3772.

(4) Smith, D.; Španěl, P.; Herbig, J.; Beauchamp, J. Mass spectrometry for real-time quantitative breath analysis. J. Breath Res. 2014, 8. 027101. 
(5) Španěl, P.; Smith, D. Account On the features, successes and challenges of selected ion flow tube mass spectrometry. Eur. J. Mass Spectrom. 2013, 19. 225-246.

(6) Broza, Y.Y.; Haick, H. Nanomaterial-based sensors for detection of disease by volatile organic compounds. Nanomedicine-Uk 2013, 8. 785-806.

(7) Wang, C.J.; Sahay, P. Breath Analysis Using Laser Spectroscopic Techniques: Breath Biomarkers, Spectral Fingerprints, and Detection Limits. Sensors 2009, 9. 8230-8262.

(8) Armenta, S.; Alcala, M.; Blanco, M. A review of recent, unconventional applications of ion mobility spectrometry (IMS). Anal. Chim. Acta 2011, 703. 114-123.

(9) Lindinger, W.; Hansel, A.; Jordan, A. On-line monitoring of volatile organic compounds at pptv levels by means of proton-transfer-reaction mass spectrometry (PTR-MS) - Medical applications, food control and environmental research. Int. J. Mass Spectrom. 1998, 173. 191-241.

(10) Biasioli, F.; Yeretzian, C.; Gasperi, F.; Mark, T.D. PTR-MS monitoring of VOCs and BVOCs in food science and technology. TrAC 2011, 30. 968-977.

(11) Keck, L.; Oeh, U.; Hoeschen, C. Corrected equation for the concentrations in the drift tube of a proton transfer reaction-mass spectrometer (PTR-MS). Int. J. Mass Spectrom. 2007, 264. 92-95.

(12) Beauchamp, J.; Herbig, J.; Dunkl, J.; Singer, W.; Hansel, A. On the performance of protontransfer-reaction mass spectrometry for breath-relevant gas matrices. Measurement Science and Technology 2013, 24. 125003.

(13) Jordan, A.; Haidacher, S.; Hanel, G.; Hartungen, E.; Herbig, J.; Märk, L.; Schottkowsky, R.; Seehauser, H.; Sulzer, P.; Märk, T.D. An online ultra-high sensitivity proton-transfer-reaction massspectrometer combined with switchable reagent ion capability (PTR+SRI-MS). Int. J. Mass Spectrom. 2009, 286. 32-38.

(14) Smith, D.; Španěl, P. Selected ion flow tube mass spectrometry (SIFT-MS) for on-line trace gas analysis. Mass Spectrom. Rev. 2005, 24. 661-700.

(15) Smith, D.; Pysanenko, A.; Španěl, P. Ionic diffusion and mass discrimination effects in the new generation of short flow tube SIFT-MS instruments. Int. J. Mass Spectrom. 2009, 281. 15-23.

(16) Michalčíková, R.B.; Španěl, P. A selected ion flow tube study of the ion molecule association reactions of protonated $\left(\mathrm{MH}^{+}\right)$, nitrosonated $\left(\mathrm{MNO}^{+}\right)$and dehydroxidated $(\mathrm{M}-\mathrm{OH})^{(+)}$carboxylic acids $(\mathrm{M})$ with $\mathrm{H}_{2} \mathrm{O}$. Int. J. Mass Spectrom. 2014, 368. 15-22.

(17) Španěl, P.; Smith, D. Advances in On-line Absolute Trace Gas Analysis by SIFT-MS. Curr. Anal. Chem. 2013, 9. 525-539.

(18) Spesyvyi, A.; Španěl, P. Determination of residence times of ions in a resistive glass selected ion flow-drift tube using the Hadamard transformation. Rapid Commun. Mass Spectrom. 2015, 29. 15631570.

(19) Gilchrist, F.J.; Razavi, C.; Webb, A.K.; Jones, A.M.; Španěl, P.; Smith, D.; Lenney, W. An investigation of suitable bag materials for the collection and storage of breath samples containing hydrogen cyanide. J. Breath Res. 2012, 6. 036004.

(20) Fontijn, A.; Clyne, M.A.A., Reactions of small transient species: kinetics and energetics. Academic Press: London, 1983.

(21) Adams, N.G.; Smith, D. Selected ion flow tube (SIFT) - technique for studying ion-neutral reactions. Int. J. Mass Spectrom. Ion Process. 1976, 21. 349-359.

(22) Mason, E.A.; McDaniel, E.W., Transport Properties of Ions in Gases. Wiley: New York, 1988.

(23) Ellis, H.W.; McDaniel, E.W.; Albritton, D.L.; Viehland, L.A.; Lin, S.L.; Mason, E.A. Transport properties of gaseous ions over a wide energy range. Part II. Atomic Data and Nuclear Data Tables 1978, 22. 179-217.

(24) Dryahina, K.; Španěl, P. A convenient method for calculation of ionic diffusion coefficients for accurate selected ion flow tube mass spectrometry, SIFT-MS. Int. J. Mass Spectrom. 2005, 244. 148-154.

(25) Španěl, P.; Dryahina, K.; Smith, D. A general method for the calculation of absolute trace gas concentrations in air and breath from selected ion flow tube mass spectrometry data. Int. J. Mass Spectrom. 2006, 249. 230-239. 
(26) Holzinger, R.; Williams, J.; Herrmann, F.; Lelieveld, J.; Donahue, N.M.; Rockmann, T. Aerosol analysis using a Thermal-Desorption Proton-Transfer-Reaction Mass Spectrometer (TD-PTR-MS): a new approach to study processing of organic aerosols. Atmospheric Chemistry and Physics 2010, 10. 22572267.

(27) Španěl, P.; Smith, D. Quantitative selected ion flow tube mass spectrometry: The influence of ionic diffusion and mass discrimination. J. Am. Soc. Mass Spectrom. 2001, 12. 863-872.

(28) McDaniel, E.W.; Mason, E.A., The Mobility and Diffusion of Ions in Gases. John Wiley: New York, 1973.

(29) Glosik, J.; Smith, D.; Španěl, P.; Freysinger, W.; Lindinger, W. SIFDT studies of the reactions of $\mathrm{C}^{+}, \mathrm{CH}^{+}$and $\mathrm{CH}_{2}{ }^{+}$with $\mathrm{HCl}$ and $\mathrm{CO}_{2}$, and $\mathrm{CH}_{3}{ }^{+}$with $\mathrm{HCl}$. Int. J. Mass Spectrom. Ion Process. 1993, 129. 131-143.

(30) Cappellin, L.; Probst, M.; Limtrakul, J.; Biasioli, F.; Schuhfried, E.; Soukoulis, C.; Mark, T.D.; Gasperi, F. Proton transfer reaction rate coefficients between $\mathrm{H} 3 \mathrm{O}+$ and some sulphur compounds. Int. J. Mass Spectrom. 2010, 295. 43-48.

(31) Fairley, D.A.; Milligan, D.B.; Freeman, C.G.; McEwan, M.J.; Španěl, P.; Smith, D. Competitive association and charge transfer in the reactions of $\mathrm{NO}^{+}$with some ketones: a selected ion flow drift tube study. Int. J. Mass Spectrom. 1999, 193. 35-43.

(32) Ikezoe, Y.; Matsuoka, S.; Takebe, M.; Viggiano, A., Gas Phase Ion-Molecule Reaction Rate Constants Through 1986. Maruzen: Tokyo, 1987.

(33) Meot-Ner (Mautner), M.M.; Lias, S.G. Binding Energies Between Ions and Molecules, and The Thermochemistry of Cluster Ions. in ed. Linstrom, P.J., Mallard, W.G. NIST Chemistry WebBook, NIST Standard Reference Database Number 69. Gaithersburg: National Institute of Standards and Technology, 2015.

(34) Lau, Y.K.; Ikuta, S.; Kebarle, P. Thermodynamics and Kinetics of the Gas-Phase Reactions $\mathrm{H}_{3} \mathrm{O}^{+}\left(\mathrm{H}_{2} \mathrm{O}\right)_{\mathrm{N}-1}+\mathrm{H}_{2} \mathrm{O}=\mathrm{H}_{3} \mathrm{O}^{+}\left(\mathrm{H}_{2} \mathrm{O}\right)_{\mathrm{N}}$. J. Am. Chem. Soc. 1982, 104. 1462-1469.

(35) Španěl, P.; Smith, D. Influence of water vapour on selected ion flow tube mass spectrometric analyses of trace gases in humid air and breath. Rapid Commun. Mass Spectrom. 2000, 14. 1898-1906. (36) Španěl, P.; Smith, D. On-line measurement of the absolute humidity of air, breath and liquid headspace samples by selected ion flow tube mass spectrometry. Rapid Commun. Mass Spectrom. 2001, 15. 563-569.

(37) Spesyvyi, A.; Španěl, P., in Proceedings of WDS 2015. MatfyzPress: Prague, 2015 in press. (38) Smith, D.; Španěl, P.; Thompson, J.M.; Rajan, B.; Cocker, J.; Rolfe, P. The Selected Ion Flow Tube Method for Workplace Analyses of Trace Gases in Air and Breath: Its Scope, Validation, and Applications. Applied occupational and environmental hygiene 1998, 13. 817-823.

(39) Španěl, P.; Smith, D. Reactions of hydrated hydronium ions and hydrated hydroxide ions, with some hydrocarbons and oxygen-bearing organic-molecules. J. Phys. Chem. 1995, 99. 15551-15556. 
For Table of Contents Only

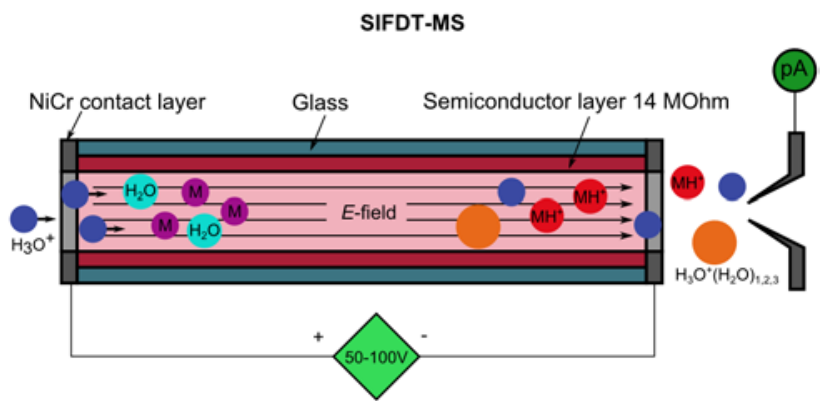

